\title{
Anticorrosion Activity of 8-Quinoline Sulphonyl Chloride on Mild Steel in 1 M HCl Solution
}

\author{
R. Ganapathi Sundaram and M. Sundaravadivelu \\ Department of Chemistry, The Gandhigram Rural Institute-Deemed University, Gandhigram, Tamil Nadu 624 302, India
}

Correspondence should be addressed to M. Sundaravadivelu; msundargri@gmail.com

Received 20 October 2015; Revised 31 January 2016; Accepted 1 February 2016

Academic Editor: Menahem Bamberger

Copyright (C) 2016 R. Ganapathi Sundaram and M. Sundaravadivelu. This is an open access article distributed under the Creative Commons Attribution License, which permits unrestricted use, distribution, and reproduction in any medium, provided the original work is properly cited.

\begin{abstract}
An anticorrosion activity of 8-quinoline sulphonyl chloride (8-QSC) on mild steel in $1 \mathrm{M} \mathrm{HCl}$ solution was studied by weight loss (WL) method and electrochemical methods, namely, electrochemical impedance spectroscopy (EIS), Tafel polarization (TP), and linear polarization resistance (LPR). Results obtained from WL method, EIS, TP, and LPR, showed that 8-QSC is a good corrosion inhibitor for mild steel in $1 \mathrm{M} \mathrm{HCl}$ solution. The results indicated that the inhibition efficiency and extent of surface coverage were increased with increase in inhibitor concentration and decrease in the corrosion rate. This is due to the formation of protective film on the surface of mild steel. Adsorption of 8-QSC on the mild steel surface was found to obey the Langmuir adsorption isotherm. A Tafel plot indicates that the used inhibitor behaves predominantly as cathodic type. The surface morphology of the mild steel was studied by Scanning Electron Microscopy (SEM) and Energy Dispersive X-Ray (EDX) Spectroscopy techniques. All the methods give the same order of inhibition efficiencies.
\end{abstract}

\section{Introduction}

Corrosion is the destruction of metals and alloys by chemical interaction with their environment. The word corrosion is sometimes use for the degradation of plastics, concrete, and wood but generally refers to active metals. Active metals like mild steel, $\mathrm{Zn}, \mathrm{Al}$, and $\mathrm{Cu}$ are employed in various industries for fabrication purposes due to their low cost and easy availability, where surfaces are rapidly damaged in acid media $[1,2]$. In order to reduce the damage (corrosion) of active metals, a number of techniques like metallic coatings, anodic protection, cathodic protection, inhibitors, and so forth, have been applied. Among the numerous anticorrosion measures, the use of organic inhibitors is one of the most economical and practical methods for protection of metals and alloys against corrosion [3-5]. The organic compounds containing nitrogen, oxygen, sulphur, and phosphorous, heterocyclic compounds with a polar functional group, and conjugated double bonded or triple bonded compounds have been widely used as acid inhibitors [6-8]. Heterocyclic compounds, such as pyridine, pyridine derivatives, pyrazole, triazole, tetrazole, and benzothiazole derivatives, have been reported and they show better inhibition efficiency for metals especially mild steel in different media $[6,9]$. The existing data show that most of the organic inhibitors act by adsorption on the metal and alloys surface [10]. Adsorption of an inhibitor by a metal surface depends on the nature and surface charge on the metal, the mode of adsorption, and the electronic structure of the inhibitor. The inhibitor molecules get bonded to the mild steel surface by chemisorption, physisorption, or complexation with the polar groups acting as the reactive centers in the molecules [11].

In the present work, we have studied an anticorrosion activity of various concentrations of 8-QSC on mild steel in $1 \mathrm{M} \mathrm{HCl}$ solution. From this work, the rate of corrosion was decreased with increasing the inhibitor concentration, Bbecause the studied inhibitor molecule contains a number of heteroatoms like oxygen, sulphur, and benzene ring with active centers like nitrogen and aromatic $\pi$ electrons.

\section{Experimental Part}

2.1. Materials Preparation. The material used in the present work is mild steel with chemical composition of (\% wt) 
$0.104 \%$ C, $0.58 \% \mathrm{Mn}, 0.035 \% \mathrm{P}, 0.026 \% \mathrm{~S}$, and the remaining $\mathrm{Fe}$, which was mechanically cut into $3.5 \times 1.5 \times 0.2 \mathrm{~cm}$ dimensions for weight loss measurements and $1.0 \times 1.0 \times$ $0.2 \mathrm{~cm}$ dimensions for SEM studies. For an electrochemical measurement, $1.0 \mathrm{~cm}^{2}$ surface area of the material was exposed to the corrosive medium and the rest was being covered by epoxy resin. The surfaces of all the specimens (weight loss, SEM, and electrochemical measurements) were polished with different grades of emery papers like $1 / 0,2 / 0$, $3 / 0,4 / 0,5 / 0,6 / 0$, and $7 / 0$, then subsequent cleaned with AR grade acetone, and finally dried.

2.2. Inhibitor Preparation. The heterocyclic compound 8QSC was received from SIGMA-ALDRICH and used as corrosion inhibitor. The molecular structure and the optimized structure of the studied inhibitor are given in Figure 1. The test solution $1 \mathrm{M} \mathrm{HCl}$ was prepared using analytical grade $37 \% \mathrm{HCl}$ and bidistilled water. The stock solution of 8QSC was made in $1 \mathrm{M} \mathrm{HCl}$ by dissolving 8-QSC in ethanol $(1 \mathrm{gm} / 50 \mathrm{~mL})$ and it is used for all experimental purposes. The various concentrations of inhibitor (50-300 ppm) solution and without the presence of inhibitor solution $(1 \mathrm{M} \mathrm{HCl})$ are taken as blank for comparison.

2.3. Weight Loss Measurements. The weight loss measurements were done according to the standard method as described earlier [12]. In this method, previously polished, degreased, and weighed mild steel specimens were immersed in $100 \mathrm{~mL}$ aerated test solutions in the absence and presence of various concentrations of inhibitor and various immersion times $(1,3$, and $6 \mathrm{hrs})$ at room temperature. After the immersion hrs, the specimens were carefully washed in acetone and weighed accurately. Duplicate experiments were also carried out on the same condition and the mean value of the weight loss is reported.

From this measurement, the corrosion rate $(W)$ was calculated by using the following equation:

$$
\text { C.R. }=W=\frac{m_{1}-m_{2}}{S t},
$$

where $m_{1}$ is the mass of the test piece before corrosion, $m_{2}$ is the mass of the test piece after corrosion, $S$ is the total surface area of the test piece, $t$ is the exposure time, and $W$ is the weight loss of test piece specimens. The surface coverage $(\theta)$ and inhibition efficiency (IE\%) was determined by the following equations:

$$
\begin{aligned}
\theta & =\left[\frac{W_{o}-W_{i}}{W_{o}}\right], \\
\operatorname{IE}(\%) & =\left[\frac{W_{o}-W_{i}}{W_{o}}\right] \times 100,
\end{aligned}
$$

where $W_{o}$ is the rate of corrosion in the absence of inhibitor and $W_{i}$ is the rate of corrosion in the presence of inhibitor, respectively.

2.4. Electrochemical Measurements. All the electrochemical measurements' potentiodynamic polarization and electrochemical impedance spectroscopy (EIS) were carried out

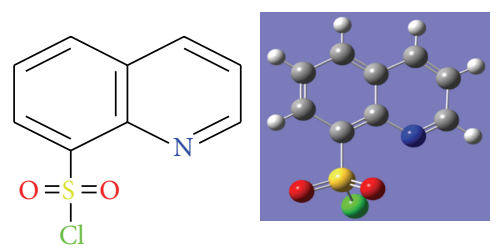

FIGURE 1: Molecular and optimized structure of studied inhibitor.

using $\mathrm{CH}$-Electrochemical analyzer model $760 \mathrm{D}$ with $\mathrm{CHI}$ $760 \mathrm{D}$ software. For these electrochemical measurements, conventional three-electrode cell systems were used. In this setup, the polished mild steel with $1.0 \mathrm{~cm}^{2}$ exposed surface area was used as working electrode, platinum electrode was used as an auxiliary electrode, and saturated calomel electrode was used as reference electrode. Before starting the electrochemical measurements, the working electrode mild steel was allowed to corrode freely with the help of $1 \mathrm{M}$ $\mathrm{HCl}$ solution without inhibitor and its open circuit potential (OCP) was recorded as a function of time up to 30 minutes, which was sufficient to attain a stable state [13]. All potentials were measured versus saturated calomel electrode.

EIS measurements were carried out by using ac impedance signal of $0.01 \mathrm{~V}$ amplitude for the frequency ranging from 0.1 to $1,0000 \mathrm{~Hz}$. Nyquist and Bode curves were obtained. From the Nyquist curves, the values of $R_{\mathrm{ct}}$, $Y_{\max }$, and $C_{\mathrm{dl}}$ of mild steel in the absence and presence of various concentrations of inhibitor in $1 \mathrm{M} \mathrm{HCl}$ solution were computed.

The Tafel curves were obtained by changing the electrode potential automatically from -300 to $+300 \mathrm{mV}$ versus the open circuit potential at a scan rate of $0.1 \mathrm{mV} / \mathrm{s}$. For the linear polarization resistance measurements, the potential of the electrode was scanned from -0.02 to $+0.02 \mathrm{~V}$ versus $E_{\text {corr }}$ at a scan rate of $0.125 \mathrm{mV} / \mathrm{s}$ [14]. All the above electrochemical measurements are repeated two times under the same condition to confirm the accuracy of the data obtained.

2.5. Surface Morphology Measurements. The surface morphology of the mild steel specimens in the absence and the presence of optimum concentration of inhibitor was analyzed using Scanning Electron Microscopy (SEM) and Energy Dispersive X-Ray (EDX) Spectroscopy, analyzing the elements present on the mild steel surface. Both SEM and EDX studies were performed on JEOL/EO JSM-6390 instrument.

\section{Results and Discussion}

3.1. Weight Loss Measurements. The values of corrosion behavior of mild steel in $1 \mathrm{M} \mathrm{HCl}$ solution in the absence and presence of various concentrations of inhibitor from weight loss measurements are given in Table 1 and Figures 2(a) and 2(b). From this study, the inhibition efficiency increases with increase in concentration of the inhibitor. However, increasing the immersion time, the inhibition efficiencies slowly decrease. The maximum efficiency $82.69 \%$ is obtained 
TABLE 1: Corrosion parameters values (weight loss studies) for mild steel in the absence and presence of various concentrations of inhibitor in $1 \mathrm{M} \mathrm{HCl}$ solution.

\begin{tabular}{lcccccccccccccc}
\hline \multirow{2}{*}{ Conc. of QSC $(\mathrm{ppm})$} & \multicolumn{3}{c}{ Weight loss $\left(\mathrm{mg} \mathrm{cm}^{-2}\right)$} & \multicolumn{3}{c}{ Corrosion rate $\left(\mathrm{mm} \mathrm{y}^{-1}\right)$} & \multicolumn{3}{c}{ Surface coverage $(\theta)$} & \multicolumn{2}{c}{$\mathrm{IE}(\%) \eta$} \\
& $1 \mathrm{~h}$ & $3 \mathrm{~h}$ & $6 \mathrm{~h}$ & $1 \mathrm{~h}$ & $3 \mathrm{~h}$ & $6 \mathrm{~h}$ & $1 \mathrm{~h}$ & $3 \mathrm{~h}$ & $6 \mathrm{~h}$ & $1 \mathrm{~h}$ & $3 \mathrm{~h}$ & $6 \mathrm{~h}$ \\
\hline Blank & 3.42 & $\mathbf{1 2 . 5 9}$ & 30.14 & 24.43 & $\mathbf{2 9 . 9 8}$ & 35.88 & - & - & - & - & - & - \\
50 & 1.80 & $\mathbf{6 . 1 3}$ & 12.38 & 12.86 & $\mathbf{1 4 . 6 0}$ & 14.74 & 0.4736 & $\mathbf{0 . 5 1 3 0}$ & 0.5892 & 47.36 & $\mathbf{5 1 . 3 0}$ & 58.92 \\
100 & 1.60 & $\mathbf{5 . 0 2}$ & 11.80 & 11.43 & $\mathbf{1 1 . 9 5}$ & 14.05 & 0.5321 & $\mathbf{0 . 6 0 1 4}$ & 0.6084 & 53.21 & $\mathbf{6 0 . 1 4}$ & 60.84 \\
150 & 1.30 & $\mathbf{4 . 1 6}$ & 9.30 & 9.29 & $\mathbf{9 . 9 0}$ & 11.07 & 0.6197 & $\mathbf{0 . 6 6 9 8}$ & 0.6915 & 61.97 & $\mathbf{6 6 . 9 8}$ & 69.15 \\
200 & 1.03 & $\mathbf{3 . 2 9}$ & 6.80 & 7.36 & $\mathbf{7 . 8 3}$ & 8.10 & 0.6987 & $\mathbf{0 . 7 3 8 8}$ & 0.7742 & 69.87 & $\mathbf{7 3 . 8 8}$ & 77.42 \\
250 & 0.80 & $\mathbf{2 . 7 0}$ & 6.40 & 5.71 & $\mathbf{6 . 4 3}$ & 7.62 & 0.7663 & $\mathbf{0 . 7 8 5 5}$ & 0.7876 & 76.63 & $\mathbf{7 8 . 5 5}$ & 78.76 \\
300 & 0.61 & $\mathbf{2 . 1 8}$ & 5.56 & 4.36 & $\mathbf{5 . 1 9}$ & 6.62 & 0.8215 & $\mathbf{0 . 8 2 6 9}$ & 0.8155 & 82.15 & $\mathbf{8 2 . 6 9}$ & 81.55 \\
\hline
\end{tabular}

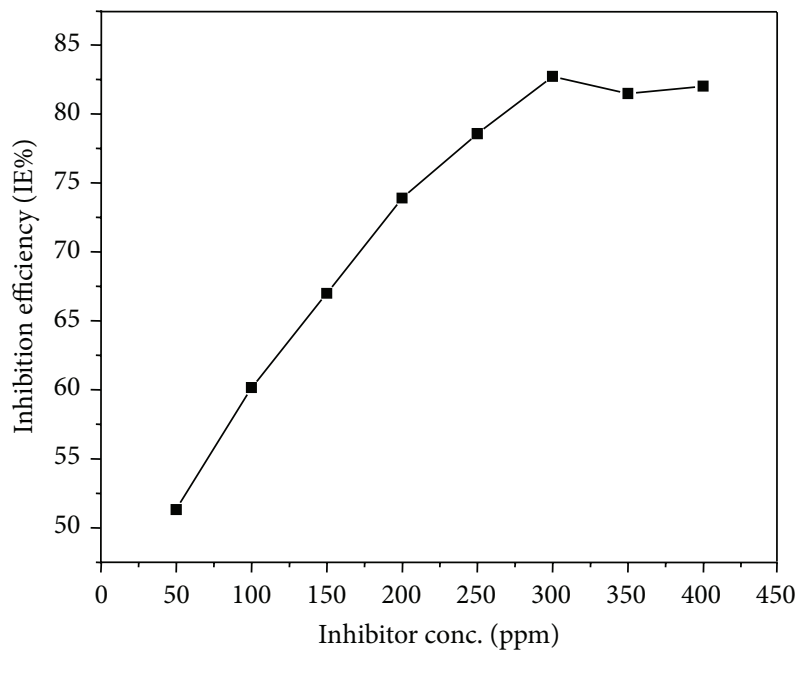

WL

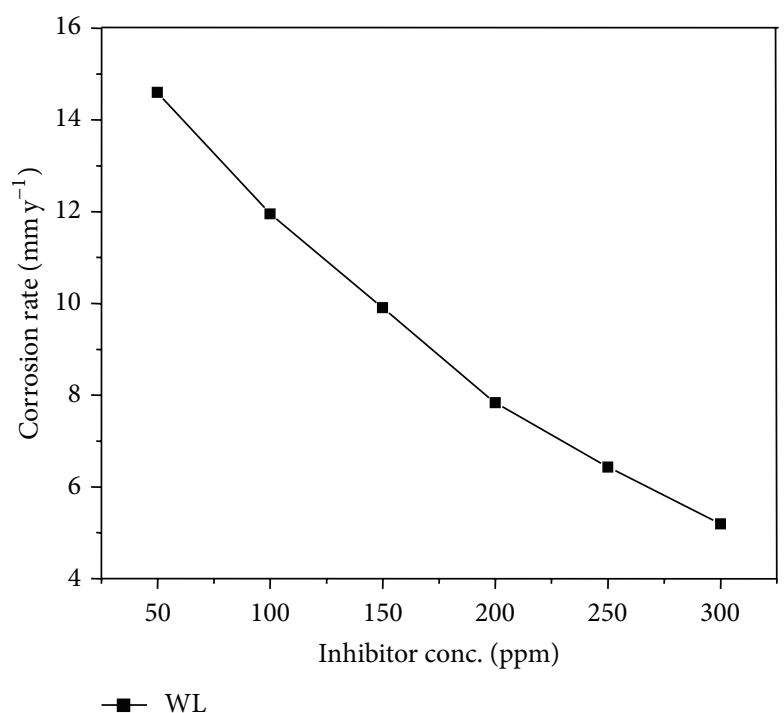

(b)

Figure 2: Weight loss values of various concentrations of inhibitor in $1 \mathrm{M} \mathrm{HCl}$ solution at room temperature: (a) variation of inhibition efficiency with different concentrations of inhibitor and (b) variation of corrosion rate with different concentrations of inhibitor.

at $300 \mathrm{ppm}$ of inhibitor solution after $3 \mathrm{~h}$ of immersion time of mild steel specimens, which explains the effect of protection of metal against corrosion due to the adsorption of studied inhibitor. Figure 2(b) shows that the corrosion rate of mild steel deceases from $14.60 \mathrm{~mm} \mathrm{y}^{-1}$ to $5.19 \mathrm{~mm} \mathrm{y}^{-1}$ on the addition of $50 \mathrm{ppm}$ to $300 \mathrm{ppm}$ of inhibitor after $3 \mathrm{~h}$ of immersion time. The increase in efficiency from $51.30 \%$ to $82.69 \%$ may be due to the blocking effect of the metal surface by adsorption and film formation mechanisms, which decreases the effective area of corrosion attack [15]. In Figure 2(a), the inhibition efficiency is increasing with inhibitor concentration the maximum efficiency is reached at a concentration of $300 \mathrm{ppm}$, while further increasing the inhibitor concentration ( 350 and $400 \mathrm{ppm}$ ) does not show any appreciable change in the efficiency. The reason for this study may be that all the active sites of surface of mild steel are completely adsorbed by the inhibitor molecule and there no empty active sites are available for further adsorption. From the weight loss measurements, we have concluded $3 \mathrm{~h}$ is the maximum time for inhibition process. The inhibiting performance exhibited by the compound may be due to the presence of protonated form of nitrogen and sulphur atoms, which makes it adsorb and form insoluble protective layer on the surface of mild steel. From these results, it is clear that the studied inhibitor 8-QSC is quickly adsorbed at the corrosion active sites of mild steel surface responsible for anticorrosion activity.

3.2. Electrochemical Impedance Spectroscopy (EIS) Measurements. The anticorrosion activity of mild steel in $1 \mathrm{M} \mathrm{HCl}$ solution in the absence and presence of various concentrations of inhibitor is investigated by EIS measurements at room temperature. EIS diagrams like Nyquist and Bode plots were obtained and are represented in Figures 3(a) and 3(b). From Figure 3(a), the Nyquist plot, it is clear that the diameter of semicircle increases with increasing the concentrations of inhibitor. The existence of single semicircle showed the single charge transfer process during dissolution which is unaffected by the presence of used inhibitor molecules. It is seen that addition of inhibitor increases the values of charge transfer resistance $\left(R_{\mathrm{ct}}\right)$ and reduces the double-layer capacitance $\left(C_{\mathrm{dl}}\right)$. The decrease in $C_{\mathrm{dl}}$ is attributed to increase 


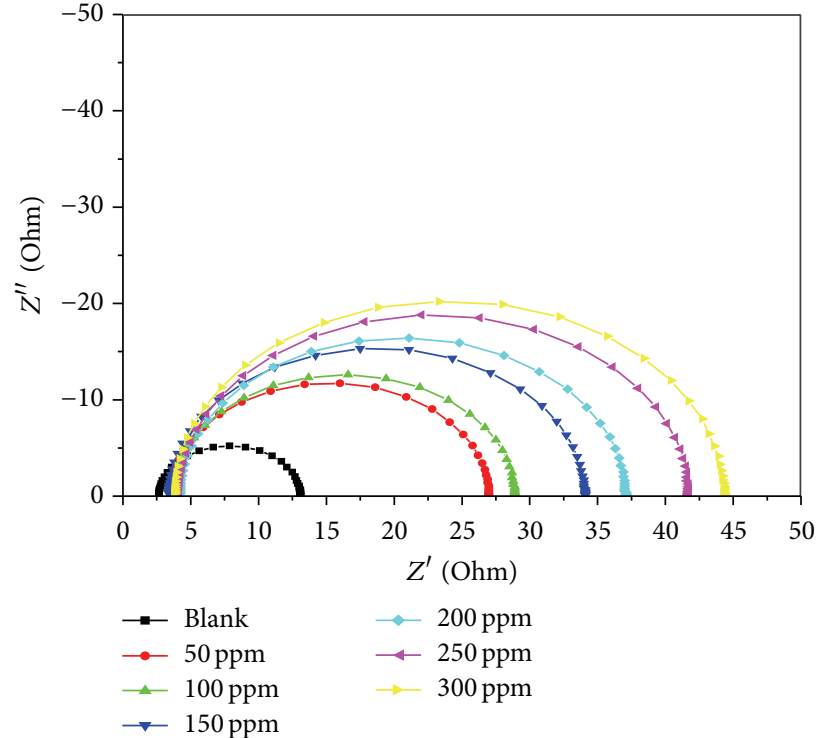

(a)

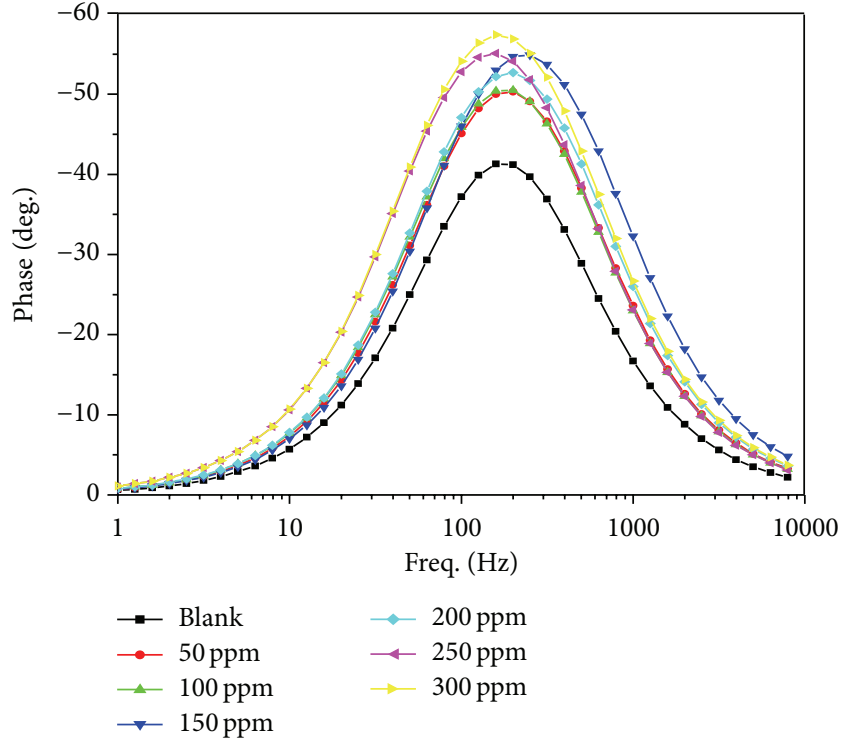

(b)

Figure 3: (a) Electrochemical impedance (Nyquist) spectrum of mild steel in $1 \mathrm{M} \mathrm{HCl}$ solution with and without various concentrations of inhibitor. (b) Electrochemical impedance (Bode) spectrum of mild steel in $1 \mathrm{M} \mathrm{HCl}$ solution with and without various concentrations of inhibitor.

TABLE 2: Electrochemical impedance spectroscopy parameters values for mild steel in $1 \mathrm{M} \mathrm{HCl}$ solution containing various concentrations of inhibitor.

\begin{tabular}{|c|c|c|c|c|c|}
\hline Conc. of QSC (ppm) & $Y_{\max }\left(\Omega \mathrm{cm}^{2}\right)$ & $R_{\mathrm{ct}}\left(\Omega \mathrm{cm}^{2}\right)$ & $C_{\mathrm{dl}}\left(\mu \mathrm{F} \mathrm{cm}^{-2}\right)$ & Surface coverage $(\theta)$ & IE $(\%) \eta$ \\
\hline Blank (1 M HCl) & 5.211 & 10.450 & 2924.17 & - & - \\
\hline 50 & 11.682 & 23.436 & 581.62 & 0.5541 & 55.41 \\
\hline 100 & 12.517 & 25.207 & 504.68 & 0.5854 & 58.54 \\
\hline 150 & 15.179 & 30.785 & 340.77 & 0.6605 & 66.05 \\
\hline 200 & 16.352 & 32.966 & 295.40 & 0.6830 & 68.30 \\
\hline 250 & 18.678 & 37.669 & 226.32 & 0.7226 & 72.26 \\
\hline 300 & 20.178 & 40.467 & 195.01 & 0.7418 & 74.18 \\
\hline
\end{tabular}

in thickness of electronic double layer [16]. The increase in $R_{\mathrm{ct}}$ value is due to the formation of protective layer on the surface of mild steel [17]. The $C_{\mathrm{dl}}$ values have been estimated from the EIS values using Nyquist plot by the following formula:

$$
C_{\mathrm{dl}}=\left(2 \pi f_{\max } R_{\mathrm{ct}}\right)^{-1} .
$$

The $C_{\mathrm{dl}}$ values were decreased with an increase in the concentrations of inhibitor. This is due to the formation of protective film on the surface of mild steel by the addition of various concentrations of inhibitor, resulting in an increase in the inhibition efficiency. The EIS parameters such as $R_{\mathrm{ct}}$, $C_{\mathrm{dl}}$, and $Y_{\max }$ are given in Table 2 . The values of IE\% obtained from the charge transfer resistances are calculated according to the following equation:

$$
\mathrm{IE}(\%)=\left[\frac{R_{\mathrm{ct}}^{i}-R_{\mathrm{ct}}^{o}}{R_{\mathrm{ct}}^{i}}\right] \times 100,
$$

where $R_{\mathrm{ct}}^{i}$ and $R_{\mathrm{ct}}^{o}$ indicate the charge transfer resistance values in the presence and absence of inhibitor, respectively.

From Figure 3(b), the phase angle at high frequencies gives a general idea of the anticorrosion activity of the inhibitor. The more negative the phase angle, the more capacitive the electrochemical behavior [18]. This is indicative of superior inhibitive behavior of inhibitor at high concentration.

3.3. Potentiodynamic Polarization Measurements. Potentiodynamic polarization measurements were carried out to study the nature of inhibitor, mode of action, and mechanism of the inhibitor reaction. Potentiodynamic polarization curves of mild steel in $1 \mathrm{M} \mathrm{HCl}$ solution in the absence and the presence of various concentrations of inhibitor are shown in Figure 4. The important potentiodynamic polarization parameters derived from these (Tafel) curves and are listed in Table 3. The inhibition efficiency (IE\%) of the inhibitor values 
TABLE 3: Potentiodynamic polarization parameters values for mild steel in $1 \mathrm{M} \mathrm{HCl}$ solution containing various concentrations of inhibitor.

\begin{tabular}{lcccccc}
\hline Conc. of QSC $(\mathrm{ppm})$ & $\beta_{a}(\mathrm{~V} / \mathrm{dec})$ & $\beta_{c}(\mathrm{~V} / \mathrm{dec})$ & $E_{\text {corr }}(\mathrm{mV} / \mathrm{SCE})$ & $I_{\text {corr }}\left(\mathrm{mA} / \mathrm{cm}^{2}\right)$ & Surface coverage $(\theta)$ & IE $(\%) \eta$ \\
\hline Blank $(1 \mathrm{M} \mathrm{HCl})$ & 6.907 & 6.374 & -263 & 1.894 & - \\
50 & 7.235 & 6.933 & -334 & 0.8914 & 0.5294 & 52.94 \\
100 & 6.963 & 7.575 & -339 & 0.7266 & 0.6164 \\
150 & 6.620 & 7.664 & -347 & 0.6788 & 0.6416 \\
200 & 7.300 & 7.038 & -355 & 0.5813 & 0.6931 \\
250 & 6.702 & 6.992 & -359 & 0.4474 & 0.7638 \\
300 & 7.119 & 7.355 & -362 & 0.3850 & 64.16 \\
\hline
\end{tabular}

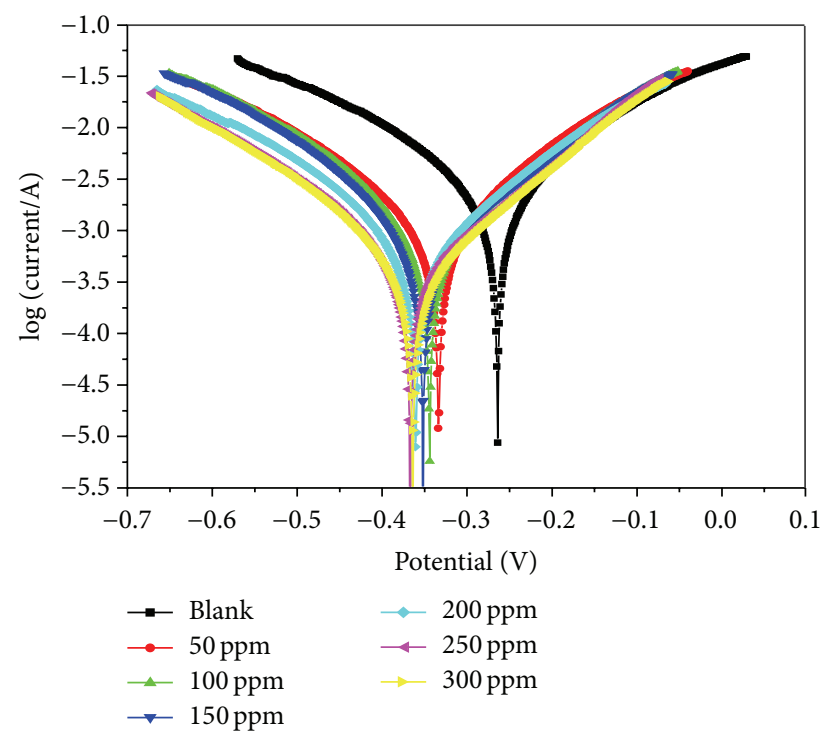

Figure 4: Potentiodynamic polarization curves of mild steel in $1 \mathrm{M}$ $\mathrm{HCl}$ solution with and without various concentrations of inhibitor.

were evaluated from calculated (from Tafel curves using CHI software) corrosion current density $\left(I_{\text {corr }}\right)$ values using the following relationship:

$$
\operatorname{IE}(\%)=\left[\frac{I_{\text {corr }}^{o}-I_{\text {corr }}^{i}}{I_{\text {corr }}^{o}}\right] \times 100,
$$

where $I_{\text {corr }}^{o}$ and $I_{\text {corr }}^{i}$ are the corrosion current density in the absence and presence of inhibitor solution, respectively. Table 3 shows that the corrosion current density $\left(I_{\text {corr }}\right)$ values decrease from $1.894 \mathrm{~mA} \mathrm{~cm}^{-2}$ to $0.3850 \mathrm{~mA} \mathrm{~cm}^{-2}$ with the addition of optimum concentrations of inhibitor. It clearly indicates $I_{\text {corr }}$ values were decreased prominently and IE\% increased with increased inhibitor concentration. The decrease of current density is due to the adsorption of inhibitor molecules on mild steel surface to retard the corrosion reaction of electrode with simultaneous replacement of electrolyte solutions at the interface [19]. From this study we observed that, on increasing the inhibitor concentration (50-300 ppm), corrosion potential $\left(E_{\text {corr }}\right)$ values were shifted towards cathodic side (negative side). However, according to Ferreira and others $[20,21]$, if the displacement of corrosion
TABLE 4: Linear polarization resistance parameters values for corrosion of mild steel in $1 \mathrm{M} \mathrm{HCl}$ solution containing various concentrations of inhibitor.

\begin{tabular}{lccc}
\hline Conc. of QSC $(\mathrm{ppm})$ & $R_{p}\left(\Omega \mathrm{cm}^{2}\right)$ & Surface coverage $(\theta)$ & IE $(\%) \eta$ \\
\hline Blank $(1 \mathrm{M} \mathrm{HCl})$ & 17 & - & - \\
50 & 34 & 0.5000 & 50.00 \\
100 & 41 & 0.5854 & 58.54 \\
150 & 45 & 0.6222 & 62.22 \\
200 & 52 & 0.6731 & 67.31 \\
250 & 71 & 0.7606 & 76.06 \\
300 & 78 & 0.7821 & 78.21 \\
\hline
\end{tabular}

potential $\left(E_{\text {corr }}\right)$ is greater than $85 \mathrm{mV}$ with respect to the corrosion potential ( $\left.E_{\text {corr }}\right)$ of the blank solution, the inhibitor can be seen as a cathodic or anodic type. In this study, the maximum displacement was $99 \mathrm{mV}$ cathodically with respect to the blank. This indicates that the studied inhibitor behaves predominantly as cathodic type.

3.4. Linear Polarization Resistance Measurements. The linear polarization resistance $\left(R_{p}\right)$ values were derived from the slope of the potential versus current lines. The inhibition efficiencies and linear polarization resistance parameters values are given in Table 4 . The inhibition efficiency (IE\%) and surface coverage $(\theta)$ were calculated using the following relationship [14]:

$$
\begin{aligned}
\theta & =\left[\frac{R_{p}^{i}-R_{p}^{o}}{R_{p}^{i}}\right], \\
\operatorname{IE}(\%) & =\left[\frac{R_{p}^{i}-R_{p}^{o}}{R_{p}^{i}}\right] \times 100,
\end{aligned}
$$

where $R_{p}^{i}$ and $R_{p}^{o}$ are the linear polarization resistance values in the presence and absence of inhibitor, respectively. The results obtained from weight loss, EIS, and Tafel polarization method showed good agreement with the results obtained from linear polarization resistance. From Table 4, it is shown there is increasing in the $R_{p}$ value and inhibition efficiency with increases in the various concentrations of inhibitor.

3.5. Adsorption Isotherm Measurements. Adsorption isotherm gives information about the interaction of the 
adsorbed molecules (inhibitor) with the electrode (mild steel) surface [22]. Two types of interaction can explain the adsorption of the inhibitors on the surface of mild steel: physisorption and chemisorption [23, 24]. The type of adsorption is mainly based on the molecular structure of the inhibitor, type of the electrolyte, and nature of the metal [25]. The surface coverage $(\theta)$ is very useful for understanding the adsorption behavior of studied inhibitor. The inhibition efficiency of used inhibitor was studied by chemical (WL) and electrochemical (EIS, Tafel, and LPR) methods, which suggest that the surface coverage was increased with increasing the inhibitor concentration. To explain the adsorption characteristics of 8-QSC, several adsorption isotherms have been tested with the $\theta$ values of all methods (WL, EIS, Tafel, and LPR) and the Langmuir adsorption isotherm model fits the experimental data well. According to Langmuir isotherm, $\theta$ is related to $C_{\text {inh }}$ by the following equation:

$$
\frac{C_{\text {inh }}}{\theta}=\frac{1}{K_{\text {ads }}}+C_{\text {inh }}
$$

where $C_{\text {inh }}$ is the inhibitor concentration (ppm), $\theta$ is the degree of surface coverage, and $K_{\mathrm{ads}}$ is the equilibrium constant of the adsorption process.

The $K_{\text {ads }}$ values can be calculated from the intercept lines on the $C_{\text {inh }} / \theta$ axis. This is related to $\Delta G_{\text {ads }}^{0}$ with the following equation:

$$
\Delta G_{\text {ads }}^{0}=-R T \ln \left(55.5 K_{\mathrm{ads}}\right),
$$

where $R$ is the universal gas constant, $T$ is the absolute temperature, and 55.5 is the concentration of water in solution in $\mathrm{mol} \mathrm{L}^{-1}$ [26]. The calculated values of $\Delta G_{\mathrm{ads}}^{0}, K_{\mathrm{ads}}$, and $R^{2}$ are given in Table 5. Figure 5 shows the straight line of $C_{\text {inh }} / \theta$ versus $C_{\text {inh }}$ for various concentrations of inhibitor at room temperature. These results show that the linear regression coefficient $\left(R^{2}\right)$ and slope are equal to unity, which confirms the adsorption of studied inhibitor on mild steel surface. Generally the calculated standard free energy $\left(\Delta G_{\text {ads }}^{0}\right)$ values up to $-20 \mathrm{~kJ} \mathrm{~mol}^{-1}$ are consistent with electrostatic interaction between the charged inhibitor molecules and the charged metal surface (physisorption) while those around $-40 \mathrm{~kJ} \mathrm{~mol}^{-1}$ or higher values are associated with chemical interaction or chemisorption as a result of sharing or transfer of electrons from the organic inhibitor molecules to the metal surface to form a coordinate covalent bond [27, 28].

In the present study, the $\Delta G_{\text {ads }}^{0}$ values obtained from weight loss method, EIS method, Tafel method, and LPR method were $-17.45,-18.82,-17.90$, and -17.53 , respectively. The above results confirmed the inhibitor adsorbed on the metal surface via physical adsorption and the adsorption process is always spontaneous.

3.6. Scanning Electron Microscopy Measurements. The surfaces of mild steel were analyzed using Scanning Electron Microscope (SEM) after the immersion of $3 \mathrm{hrs}$ in $1 \mathrm{M} \mathrm{HCl}$ solution in the absence and presence of optimum concentration $(300 \mathrm{ppm})$ of inhibitor. The SEM images of polished mild steel, $1 \mathrm{M} \mathrm{HCl}$ solution without inhibitor, and $1 \mathrm{M}$
TABLE 5: Thermodynamic parameters values derived from Langmuir isotherm for adsorption of optimum concentration of inhibitor on mild steel in $1 \mathrm{M} \mathrm{HCl}$ solution at room temperature.

\begin{tabular}{lccc}
\hline Method & $R^{2}$ & $K_{\mathrm{ads}}\left(10^{4} \mathrm{M}^{-1}\right)$ & $\Delta G_{\mathrm{ads}}^{0}\left(\mathrm{~kJ} \mathrm{~mol}^{-1}\right)$ \\
\hline Weight loss & 0.9927 & 18.3600 & -17.45 \\
EIS & 0.9961 & 31.6902 & -18.82 \\
Tafel & 0.9877 & 21.9559 & -17.90 \\
LPR & 0.9847 & 18.9345 & -17.53 \\
\hline
\end{tabular}

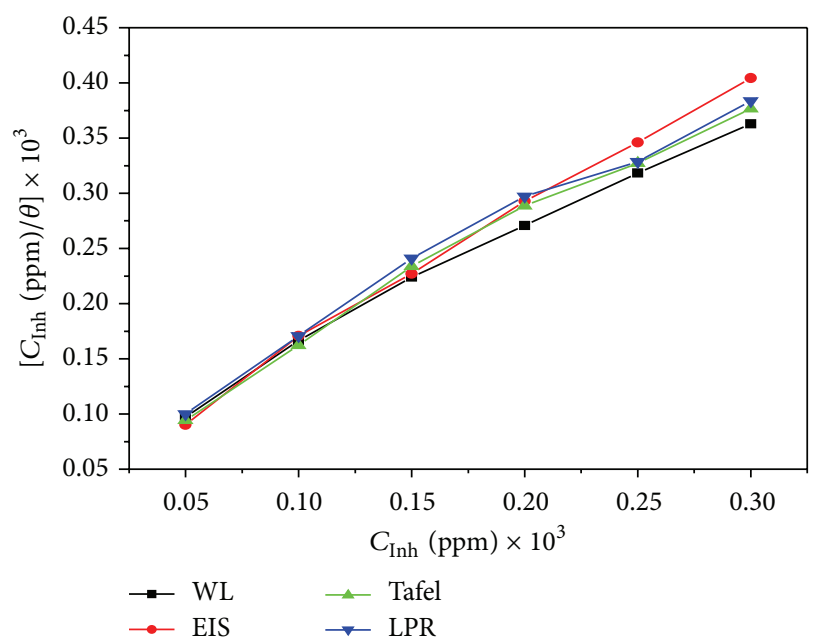

FIGURE 5: Langmuir adsorption isotherm plot (using WL, EIS, Tafel, and LPR results) for the adsorption of the inhibitor in $1 \mathrm{M} \mathrm{HCl}$ solution on the surface of mild steel.

$\mathrm{HCl}$ solution with inhibitor are given in Figures 6(a)-6(c). This study clearly indicates that the anticorrosion activity is increased remarkably in the presence of inhibitor.

3.7. Energy Dispersive X-Ray Spectroscopy (EDX) Measurements. The Energy Dispersive X-Ray (EDX) Spectroscopy technique was employed in order to get information about the percentage of atomic composition of the surface of the polished mild steel, in the absence and presence of optimum concentration of inhibitors in $1 \mathrm{M} \mathrm{HCl}$ solution. The results of EDX spectra were given in Figures 7(a)-7(c).

The atomic contents (\%) of various elements in the polished, corroded, and inhibited mild steel surfaces were analyzed by EDX and are given in Table 6 . From Table 6, the percentage atomic content of iron $(\mathrm{Fe})$ is decreased from 87.05 (polished mild steel) to 30.93 (inhibited mild steel). From Figure 7(c), the EDX spectra of inhibited samples show that the Fe peaks are remarkably suppressed, when compared with the EDX spectra of polished (Figure 7(a)) and corroded (Figure 7(b)) mild steel samples. The above suppression of Fe peaks is due to the formation of protective film on the surface of mild steel. This study is further supportive evidence of formation of protective layer on the surface of mild steel. 


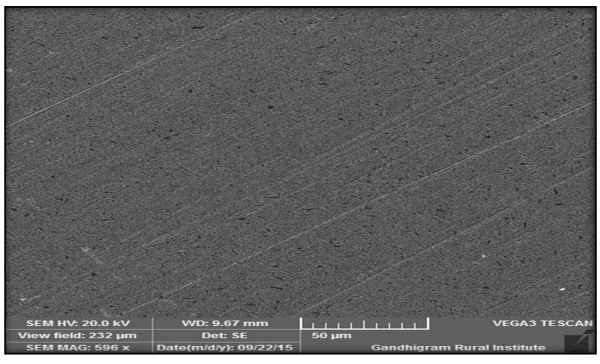

(a)

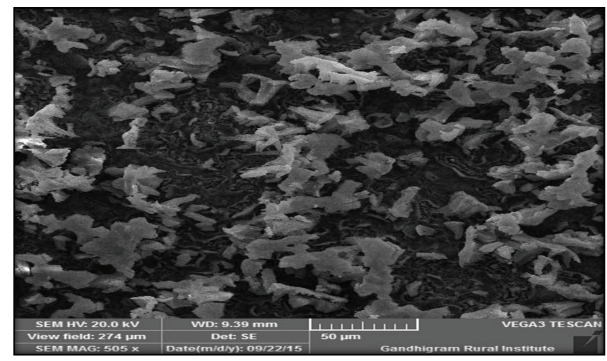

(b)

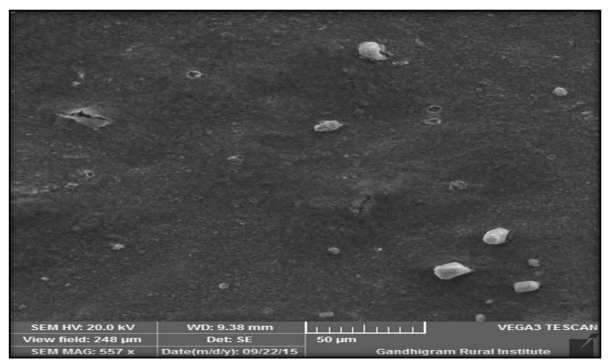

(c)

FIGURE 6: SEM images of the surface of mild steel: (a) polished mild steel, (b) after immersion in $1 \mathrm{M} \mathrm{HCl} \mathrm{solution} \mathrm{in} \mathrm{absence} \mathrm{of} \mathrm{inhibitor,}$ and (c) after immersion in $1 \mathrm{M} \mathrm{HCl}$ solution in presence of optimum concentration of inhibitor.

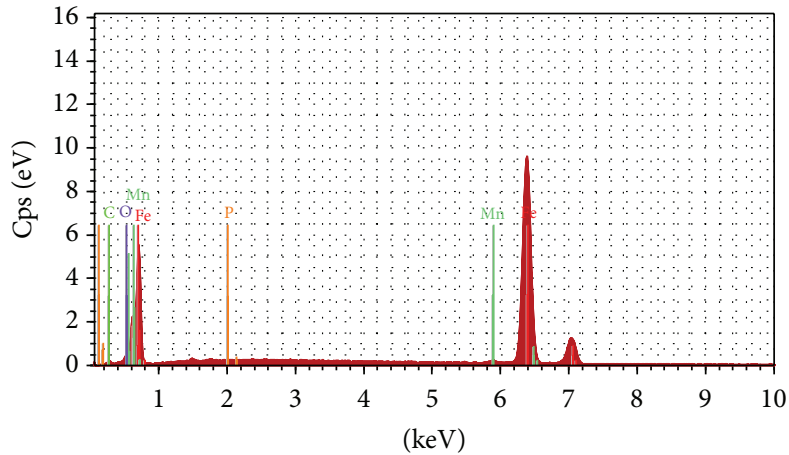

(a)

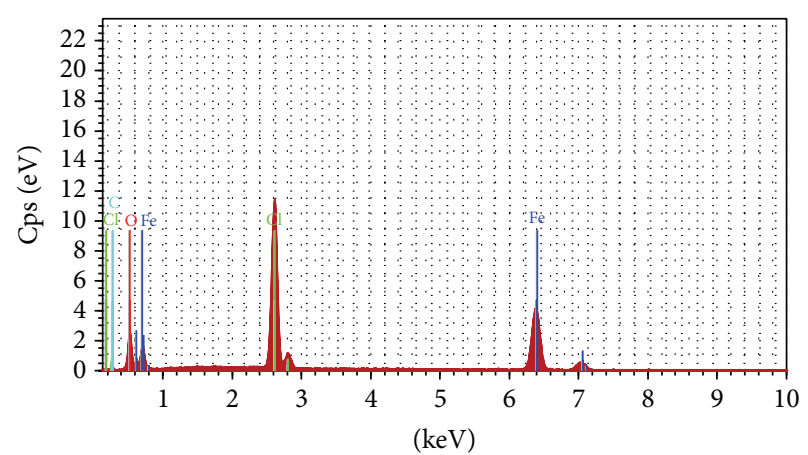

(b)

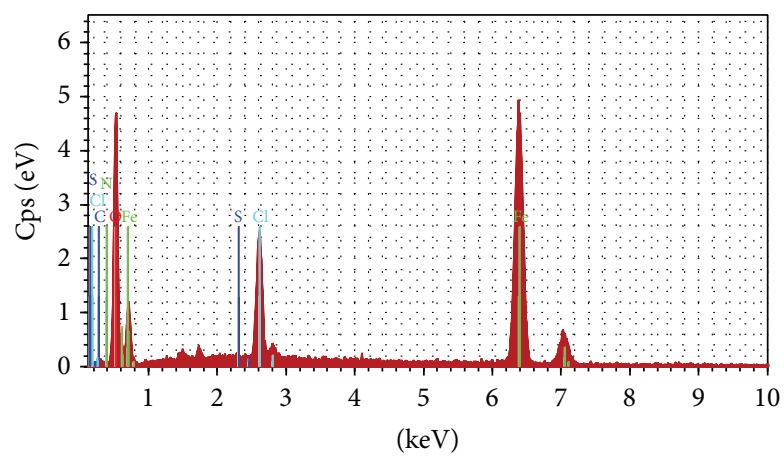

(c)

FIGURE 7: EDX spectra of mild steel: (a) polished mild steel, (b) after immersion in $1 \mathrm{M} \mathrm{HCl}$ solution in absence of inhibitor, and (c) after immersion in $1 \mathrm{M} \mathrm{HCl}$ solution in presence of optimum concentration of inhibitor. 
TABLE 6: Percentage atomic contents of elements obtained from EDX spectra on mild steel surface.

\begin{tabular}{|c|c|c|c|c|c|c|c|c|}
\hline Sample & $\mathrm{Fe}$ & $\mathrm{C}$ & $\mathrm{O}$ & $\mathrm{Mn}$ & $\mathrm{P}$ & $\mathrm{Cl}$ & $\mathrm{N}$ & S \\
\hline Polished mild steel & 87.05 & 10.94 & 1.66 & 0.27 & 0.08 & - & - & - \\
\hline Corroded mild steel & 41.98 & 13.02 & 23.02 & - & - & 21.97 & - & - \\
\hline Inhibited mild steel & 30.93 & 4.40 & 58.14 & - & - & 5.63 & 0.79 & 0.10 \\
\hline
\end{tabular}

\section{Conclusion}

From the studies, the following points are concluded:

(i) 8-QSC is found to be a good anticorrosion organic molecule of mild steel in $1 \mathrm{M} \mathrm{HCl}$ solution.

(ii) Anticorrosive activity was increased with increase in inhibitor concentration.

(iii) EIS study proved that the studied inhibitor follows adsorption mechanism and controls the corrosion of mild steel in $1 \mathrm{M} \mathrm{HCl}$ solution.

(iv) Polarization studies reveal that 8-QSC acts as a predominantly cathodic inhibitor.

(v) The adsorption of studied inhibitor on the mild steel surface obeys Langmuir adsorption isotherm.

(vi) The values of $\Delta G^{0}$ in all methods indicate that the inhibitor inhibits the corrosion of mild steel by strong physisorption.

(vii) Inhibition efficiency obtained from weight loss measurements was in good agreement with EIS, Tafel, and LPR methods.

(viii) SEM and EDX studies confirmed the formation of inhibitor film on the surface of mild steel.

\section{Conflict of Interests}

The authors declare that there is no conflict of interests regarding the publication of this paper.

\section{References}

[1] G. Shahi, C. B. Verma, E. E. Ebenso, and M. A. Quiraishi, "Thermodynamic and electrochemical investigation of (9-[(R) 2[[bis[[(isopropoxycarbonyl)oxy] methoxy] phosphinyl] methoxy]propyl] adenine fumarate) as green corrosion inhibitor for mild steel in $1 \mathrm{M} \mathrm{HCl,"} \mathrm{International} \mathrm{Journal} \mathrm{of} \mathrm{Electrochem-}$ ical Science, vol. 10, pp. 1102-1116, 2015.

[2] A. N. Senthilkumar, K. Tharini, and M. G. Sethuraman, "Corrosion inhibitory effect of few piperidin-4-one oximes on mild steel in hydrochloric acid medium," Surface Review and Letters, vol. 16, no. 1, pp. 141-147, 2009.

[3] M. Yadav, S. Kumar, I. Bahadur, and D. Ramjugernath, "Corrosion inhibitive effect of synthesized thiourea derivatives on mild steel in a $15 \% \mathrm{HCl}$ solution," International Journal of Electrochemical Science, vol. 9, no. 11, pp. 6529-6550, 2014.

[4] A. A. Al-Sarawy, A. S. Fouda, and W. A. S. El-Dein, "Some thiazole derivatives as corrosion inhibitors for carbon steel in acidic medium," Desalination, vol. 229, no. 1-3, pp. 279-293, 2008.
[5] B. Hammouti, A. Dafali, R. Touzani, and M. Bouachrine, "Inhibition of copper corrosion by bipyrazole compound in aerated 3\% NaCl," Journal of Saudi Chemical Society, vol. 16, no. 4, pp. 413-418, 2012.

[6] R. Karthik, G. Vimaladevi, S.-M. Chen, A. Elangovan, B. Jeyaprabha, and P. Prakash, "Corrosion inhibition and adsorption behavior of 4-amino acetophenone pyridine 2-aldehyde in $1 \mathrm{M}$ hydrochloric acid," International Journal of Electrochemical Science, vol. 10, pp. 4666-4681, 2015.

[7] K. F. Khaled, "Monte Carlo simulations of corrosion inhibition of mild steel in $0.5 \mathrm{M}$ sulphuric acid by some green corrosion inhibitors," Journal of Solid State Electrochemistry, vol. 13, no. 11, pp. 1743-1756, 2009.

[8] G. Gao, C. H. Liang, and H. Wang, "Synthesis of tertiary amines and their inhibitive performance on carbon steel corrosion," Corrosion Science, vol. 49, no. 4, pp. 1833-1846, 2007.

[9] M. A. Quraishi and D. Jamal, "Corrosion inhibition of N-80 steel and mild steel in $15 \%$ boiling hydrochloric acid by a triazole compound-SAHMT," Materials Chemistry and Physics, vol. 68, no. 1-3, pp. 283-287, 2001.

[10] H. Ashassi-Sorkhabi and M. Es'haghi, "Corrosion inhibition of mild steel in acidic media by [BMIm] Br Ionic liquid," Materials Chemistry and Physics, vol. 114, no. 1, pp. 267-271, 2009.

[11] I. Lukovits, E. Kálmán, and F. Zucchi, "Corrosion inhibitorscorrelation between electronic structure and efficiency," Corrosion, vol. 57, no. 1, pp. 3-8, 2001.

[12] R. Ganapathi Sundaram, G. Karthik, G. Vengatesh, and M. Sundaravadivelu, "Adsorption characteristics of Kynurenic acid as green corrosion inhibitor at mild steel / hydrochloric acid interface," Der Chemica Sinica, vol. 6, no. 7, pp. 54-63, 2015.

[13] R. Ganapathi Sundaram, M. Sundaravadivelu, G. Karthik, and G. Vengatesh, "Inhibition effect of 4-hydroxyquinoline-2carboxylic acid on corrosion of mild steel in $1 \mathrm{M}$ sulphuric acid solution," Journal of Chemical and Pharmaceutical Research, vol. 7, no. 9, pp. 823-835, 2015.

[14] Sudheer and M. A. Quraishi, "Effect of pharmaceutically active compound omeprazole, on the corrosion of mild steel in hydrochloric acid solution," Journal of Chemical and Pharmaceutical Research, vol. 3, no. 5, pp. 82-92, 2011.

[15] T. Zhao and G. Mu, "The adsorption and corrosion inhibition of anion surfactants on aluminium surface in hydrochloric acid," Corrosion Science, vol. 41, no. 10, pp. 1937-1944, 1999.

[16] M. G. Hosseini, M. Ehteshamzadeh, and T. Shahrabi, "Protection of mild steel corrosion with Schiff bases in $0.5 \mathrm{M} \mathrm{H}_{2} \mathrm{SO}_{4}$ solution," Electrochimica Acta, vol. 52, no. 11, pp. 3680-3685, 2007.

[17] F. Bentiss, M. Traisnel, and M. Lagrenee, "The substituted 1,3,4oxadiazoles: a new class of corrosion inhibitors of mild steel in acidic media," Corrosion Science, vol. 42, no. 1, pp. 127-146, 2000.

[18] M. Mahdavian and S. Ashhari, "Corrosion inhibition performance of 2-mercaptobenzimidazole and 2-mercaptobenzoxazole compounds for protection of mild steel in hydrochloric acid solution," Electrochimica Acta, vol. 55, no. 5, pp. 1720-1724, 2010. 
[19] K. Stanly Jacob and G. Parameswaran, "Corrosion inhibition of mild steel in hydrochloric acid solution by Schiff base furoin thiosemicarbazone," Corrosion Science, vol. 52, no. 1, pp. 224228,2010

[20] W.-H. Li, Q. He, S.-T. Zhang, C.-L. Pei, and B.-R. Hou, "Some new triazole derivatives as inhibitors for mild steel corrosion in acidic medium," Journal of Applied Electrochemistry, vol. 38, no. 3, pp. 289-295, 2008.

[21] E. S. Ferreira, C. Giacomelli, F. C. Giacomelli, and A. Spinelli, "Evaluation of the inhibitor effect of L-ascorbic acid on the corrosion of mild steel," Materials Chemistry and Physics, vol. 83, no. 1, pp. 129-134, 2004.

[22] E. A. Noor and A. H. Al-Moubaraki, "Thermodynamic study of metal corrosion and inhibitor adsorption processes in mild steel/1-methyl-4[4'(-X)-styryl pyridinium iodides/hydrochloric acid systems," Materials Chemistry and Physics, vol. 110, no. 1, pp. 145-154, 2008.

[23] L. Larabi, O. Benali, and Y. Harek, "Corrosion inhibition of copper in $1 \mathrm{M} \mathrm{HNO}_{3}$ solution by $\mathrm{N}$-phenyl oxalic Dihydrazide and oxalic N-phenylhydrazide $\mathrm{N}^{\prime}$-phenylthiosemicarbazide," Portugaliae Electrochimica Acta, vol. 24, no. 3, pp. 337-346, 2006.

[24] L. Larabi, Y. Harek, M. Traisnel, and A. Mansri, "Synergistic influence of poly(4-vinylpyridine) and potassium iodide on inhibition of corrosion of mild steel in $1 \mathrm{M} \mathrm{HCl,"} \mathrm{Journal} \mathrm{of}$ Applied Electrochemistry, vol. 34, no. 8, pp. 833-839, 2004.

[25] M. A. Ameer and A. M. Fekry, "Inhibition effect of newly synthesized heterocyclic organic molecules on corrosion of steel in alkaline medium containing chloride," International Journal of Hydrogen Energy, vol. 35, no. 20, pp. 11387-11396, 2010.

[26] O. Olivares, N. V. Likhanova, B. Gómez et al., "Electrochemical and XPS studies of decylamides of $\alpha$-amino acids adsorption on carbon steel in acidic environment," Applied Surface Science, vol. 252, no. 8, pp. 2894-2909, 2006.

[27] I. Ahamad, R. Prasad, and M. A. Quraishi, "Thermodynamic, electrochemical and quantum chemical investigation of some Schiff bases as corrosion inhibitors for mild steel in hydrochloric acid solutions," Corrosion Science, vol. 52, no. 3, pp. 933-942, 2010.

[28] A. Yurt, G. Bereket, A. Kivrak, A. Balaban, and B. Erk, "Effect of Schiff bases containing pyridyl group as corrosion inhibitors for low carbon steel in $0.1 \mathrm{M} \mathrm{HCl}$," Journal of Applied Electrochemistry, vol. 35, no. 10, pp. 1025-1032, 2005. 

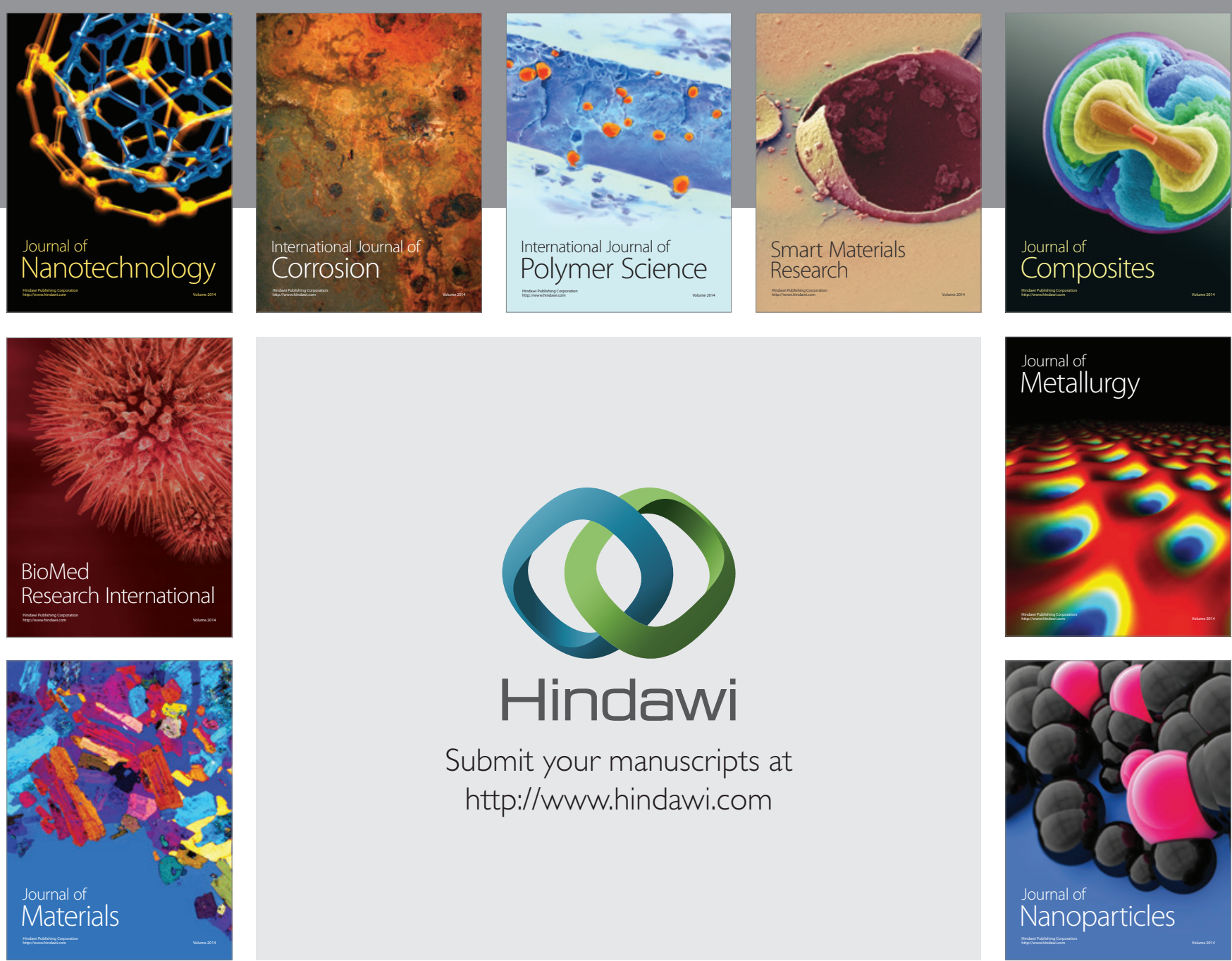

\section{Hindawi}

Submit your manuscripts at

http://www.hindawi.com

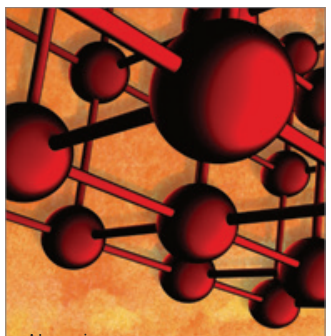

Materials Science and Engineering
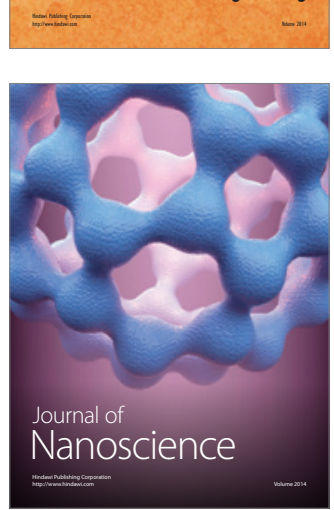
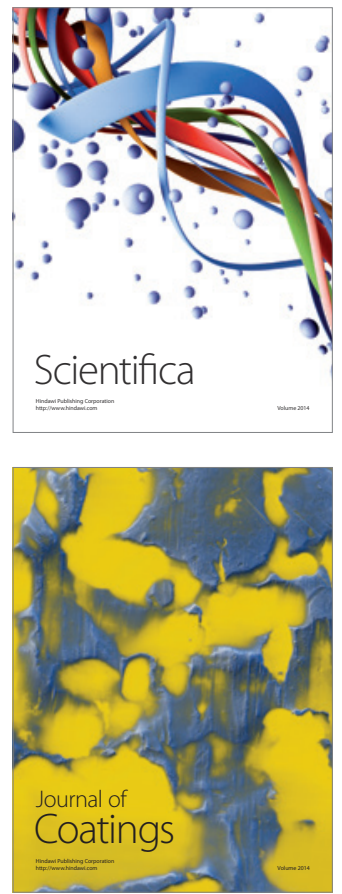
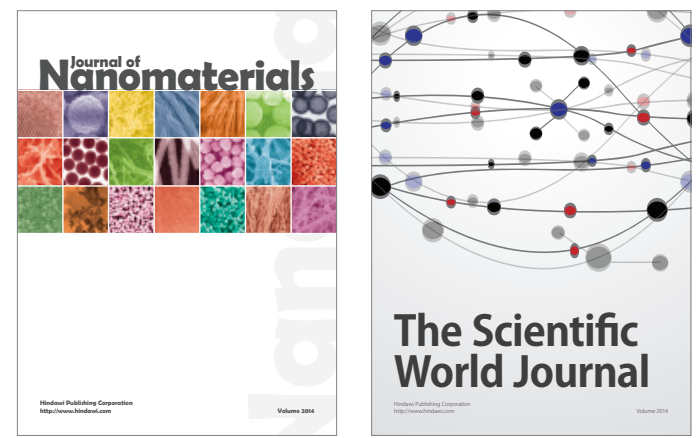

The Scientific World Journal
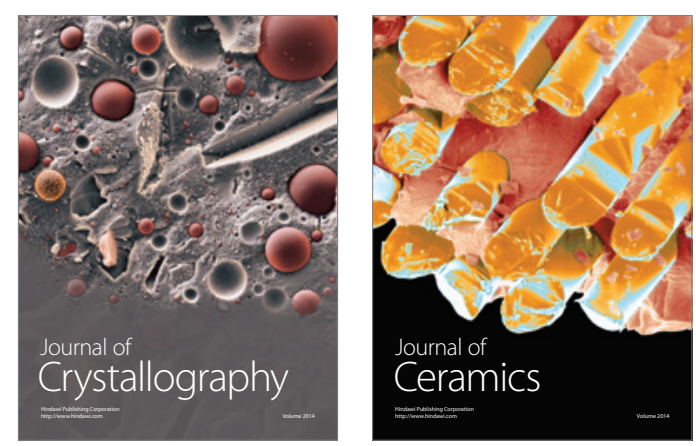
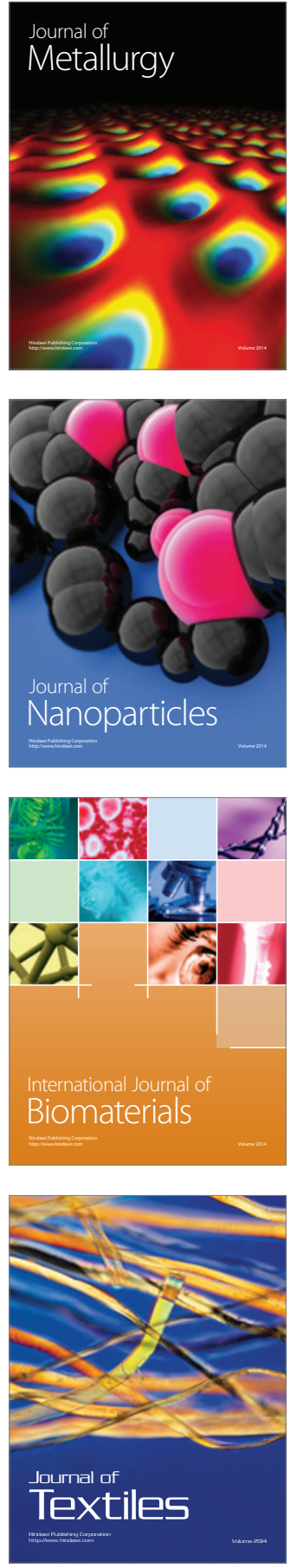